\title{
Encoding of Touch Intensity But Not Pleasantness in Human Primary Somatosensory Cortex
}

\author{
닐 K. Case, ${ }^{1}$ Claire M. Laubacher, ${ }^{1}$ Håkan Olausson,,${ }^{3}$ Binquan Wang, ${ }^{1}$ Primavera A. Spagnolo, ${ }^{2}$ \\ and ${ }^{\circ}$ M. Catherine Bushnell ${ }^{1}$ \\ ${ }^{1}$ National Center for Complementary and Integrative Health and ${ }^{2}$ National Institute on Alcohol Abuse and Alcoholism, National Institutes of Health, \\ Bethesda, Maryland 20892, and ${ }^{3}$ Department of Clinical and Experimental Medicine, Linköping University, 58183 Linköping, Sweden
}

Growing interest in affective touch has delineated a neural network that bypasses primary somatosensory cortex (S1). Several recent studies, however, have cast doubt on the segregation of touch discrimination and affect, suggesting that S1 also encodes affective qualities. We used functional magnetic resonance imaging (fMRI) and repetitive transcranial magnetic stimulation (rTMS) to examine the role of $S 1$ in processing touch intensity and pleasantness. Twenty-six healthy human adults rated brushing on the hand during fMRI. Intensity ratings significantly predicted activation in S1, whereas pleasantness ratings predicted activation only in the anterior cingulate cortex. Nineteen subjects also received inhibitory rTMS over right hemisphere S1 and the vertex (control). After S1 rTMS, but not after vertex rTMS, sensory discrimination was reduced and subjects with reduced sensory discrimination rated touch as more intense. In contrast, rTMS did not alter ratings of touch pleasantness. Our findings support divergent neural processing of touch intensity and pleasantness, with affective touch encoded outside of $S 1$.

Key words: affect; c-tactile fibers; pleasantness; rTMS; somatosensory cortex; touch discrimination

\section{Significance Statement}

Growing interest in affective touch has identified a neural network that bypasses primary somatosensory cortex (S1). Several recent studies, however, cast doubt on the separation of touch discrimination and affect. We used functional magnetic resonance imaging and repetitive transcranial magnetic stimulation to demonstrate the representation of touch discrimination and intensity in S1, but the representation of pleasantness in the anterior cingulate cortex, not S1. Our findings support divergent neural processing of touch intensity and pleasantness, with affective touch encoded outside of S1. Our study contributes to growing delineation of the affective touch system, a crucial step in understanding its dysregulation in numerous clinical conditions such as autism, eating disorders, depression, and chronic pain.

\section{Introduction}

Both the affective and discriminative aspects of touch are critically important in everyday life. Discriminative aspects of touch support object recognition and motor activities and socially relevant tactile information may allow the detection of hedonic environmental features that serve the well-being and homeostasis of the organism (Craig, 2013). Extensive research has identified the role of primary somatosensory cortex $(\mathrm{S} 1)$ in discriminative as-

Received March 18, 2015; revised April 19, 2016; accepted April 21, 2016.

Author contributions: L.K.C., H.O., P.A.S., and M.C.B. designed research; L.K.C., C.M.L., and B.W. performed research; L.K.C., C.M.L., and B.W. analyzed data; L.K.C., C.M.L., H.O., and M.C.B. wrote the paper.

This work was supported by the Intramural Research program of the National Center for Complementary and Integrative Health-National Institutes of Health. We thank John Gracely, Marta Ceko, and Mark Hallett for assistance with the experimental design and data analysis.

Correspondence should be addressed to Dr. Laura Case, National Center for Complementary and Integrative Health, National Institutes of Health, Building 10, CRC Room 4-1730, MSC 1302, Bethesda, MD 20892. E-mail: laura.case@nih.gov.

DOI:10.1523/JNEUROSCI.1130-15.2016

Copyright $\odot 2016$ the authors $\quad 0270-6474 / 16 / 365850-11 \$ 15.00 / 0$ pects of somatosensation, including tactile detection thresholds (Cohen et al., 1991), temporal frequency discrimination (Knecht et al., 2003), two-point discrimination (2PD; Tegenthoff et al., 2005), and tactile direction discrimination (Lundblad et al., 2011). However, the role of $S 1$ in the affective dimension of somatosensation is under dispute.

A growing body of research on C-tactile (CT) afferents has characterized an affective touch network that appears to bypass S1. CT afferents are a class of peripheral unmyelinated C-fibers that respond preferentially to slow stroking of the hairy skin and in which firing rate correlates with subjective ratings of touch pleasantness (Löken et al., 2009). Two rare patients selectively lacking $\mathrm{A} \beta$ afferents (with $\mathrm{C}$ fibers intact; Sterman et al., 1980) exhibited impoverished touch discrimination, yet reported pleasure and showed a robust response in the insula, but not S1, when their hairy skin was stroked at CT-optimal speeds (Olausson et al., 2002, 2008). Although CT-optimized stimuli also activate $\mathrm{S} 1$ cortex in healthy subjects, correlations with rat- 
ings of touch pleasantness have been reported only in other regions, including the orbitofrontal cortex (OFC; McCabe et al., 2008) and the insula (Kress et al., 2011).

Despite the evidence that touch pleasantness is processed outside of S1, several recent studies challenge this model, showing correlations between ratings of touch pleasantness and activation of S1 (though in opposite directions; McCabe et al., 2008; Gazzola et al., 2012). These studies demonstrate possible modulation of S1 by social context, but contain confounds related to attention and motivation and do not demonstrate the causal necessity of S1 in the perception of touch pleasantness. These studies also did not test bottom-up sensory contributions to touch pleasantness, such as the contribution of CT-optimal touch.

The current study focuses on affective qualities conveyed by the physical touch stimulus, rather than through top-down modulation of touch processing by social context. We used both functional magnetic resonance imaging ( $\mathrm{fMRI} ; n=26$ ) and repetitive transcranial magnetic stimulation (rTMS; $n=19$ ) to test the involvement of S1 in representing the pleasantness and intensity of touch. During the fMRI portion of our experiment, we administered slow and fast brushing to hairy and glabrous skin of the hand to produce differential activation of CT fibers and collected subjects' ratings of pleasantness. This variable CT activation afforded manipulation of touch pleasantness without altering the texture or physical intensity of the touch stimuli, allowing us to look for stimulus-driven neural representation of touch pleasantness. However, intensity and pleasantness ratings vary by brushing speed even when administered by a robot exerting constant force (Triscoli et al., 2013). We therefore also collected intensity ratings to account for differences in intensity perception in our analyses.

We then used $1 \mathrm{~Hz}$ rTMS over right hemisphere $\mathrm{S} 1$ to causally test the necessity of $\mathrm{S} 1$ activity for the perception of touch pleasantness. Low-frequency rTMS of $\sim 0.2-1 \mathrm{~Hz}$ produces a period of cortical inhibition (Chen et al., 1997; Maeda et al., 2000; Hallett, 2007) and is often used to deactivate a brain region temporarily to examine its direct causal contribution to a particular percept or behavior (Hallett, 2007; Wassermann and Zimmermann, 2012). A number of studies performing rTMS directed at S1 show perceptual changes in tactile detection thresholds, as well as spatial and temporal discrimination of tactile stimuli (Knecht et al., 2003; Tegenthoff et al., 2005; Schneider et al., 2010; Vidoni et al., 2010). Subjects rated the intensity and pleasantness of gentle touch before and after rTMS to S1 or to the vertex (control). We also tested 2PD at multiple distances as a positive control to confirm rTMS deactivation of S1. We hypothesized that S1 activation during fMRI would correlate with ratings of stimulus intensity, but not pleasantness, and that a temporary reduction of $\mathrm{S} 1$ activation would alter discriminative touch, but not pleasantness.

\section{Materials and Methods \\ Participants}

Twenty-six healthy right-handed adults (mean age $=24.8 \pm 7.0$ years; range $=19-43 ; 11$ male) participated in the MRI data analysis. Nineteen of the subjects (11 male) returned for TMS and successfully completed both TMS sessions (one additional subject was excluded due to inattention during sensory testing and one subject dropped out of the study due to discomfort during the initial TMS pulses). Each subject provided informed consent in accordance with approval from the National Institutes of Health's CNS Institutional Review Board. Participants were compensated monetarily for each study session.

\section{Experimental design}

Subjects participated in four study sessions that took place on separate days: screening, MRI, TMS session 1, and TMS session 2 .

\section{Screening}

Subjects were screened for psychological conditions by an experimenter using the MINI (Sheehan et al., 1998). Screening for major medical conditions was conducted by a nurse practitioner who conducted a brief medical examination and asked participants questions about their medical history. A urine drug test was conducted. Participants were excluded for major medical and psychological conditions (past or present), substance and alcohol dependence or abuse, chronic pain, current pregnancy, non-right-handedness, dermatological abnormalities relevant to somatosensation, and abnormal sensory acuity on the palm of the hand (2PD performance below chance levels). Participants were also screened for MRI safety and TMS safety (Rossi et al., 2009).

\section{MRI session}

The MRI session included a structural scan, a functional hand motor cortex localizer, and two functional scans collected during slow and fast brushing on the palm and back of the left hand.

\section{Motor localizer task}

Participants moved their left thumb during four $30 \mathrm{~s}$ movement blocks separated by $30 \mathrm{~s}$ of rest in response to visual prompts.

\section{Brushing blocks}

Participants received somatosensory brushing stimulation across $6 \mathrm{~cm}$ of the palm or back of the hand. The order of brushing of these two hand locations was counterbalanced across participants. A trained experimenter brushed each participant in the proximo-distal direction with a 3 -inch-diameter goat-hair watercolor brush. Audio cues allowed the experimenter to brush at a constant velocity. Each scan was composed of 4 randomly ordered blocks: 2 blocks of slow brushing $(3 \mathrm{~cm} / \mathrm{s})$ and 2 blocks of fast brushing $(30 \mathrm{~cm} / \mathrm{s})$. Each block was composed of 8 trials of $6 \mathrm{~s}$ of brushing, followed by a rest period jittered around $15 \mathrm{~s}$ (Fig. 1) to prevent significant CT fiber fatigue (Vallbo et al., 1999). After each block, participants rated the brushing on two 100-point VAS scales for intensity (anchored at $0=$ no sensation and $100=$ the most intense sensation imaginable $)$ and pleasantness $(0=$ very unpleasant; $50=$ neutral; $100=$ very pleasant) using a button response box. Two buttons were used to move the cursor left and right on the Visual Analogue Scale (VAS) scale, which was displayed to the subject on the projector screen. Participants were trained on the rating scales and use of the response box before entering the scanner. The 100 point VAS scales are one of the most common forms of rating scale used in experimental studies of pain. Studies have demonstrated that subjects can rate the intensity and pleasantness/unpleasantness of touch stimuli independently of one another (Rainville et al., 1992) and these scales are sensitive to divergent effects of mood induction on pain intensity and (un)pleasantness (Villemure et al., 2003; Loggia et al., 2008).

\section{Imaging parameters}

Images were acquired on a Siemens Skyra 3T scanner. A whole-brain T1-weighted anatomical scan was acquired with an MPRAGE sequence $(\mathrm{TR}=1900 \mathrm{~ms} ; \mathrm{TE}=2.07 \mathrm{~ms} ; \mathrm{FOV}=256 \mathrm{~mm}$; image matrix $=256 \times$ 256; number of slices $=192$; voxel size $=1 \times 1 \times 1 \mathrm{~mm}$ ). Whole-brain functional images were acquired using a T2-weighted echoplanar imaging (EPI) sequence sensitive to BOLD contrast $(\mathrm{TR}=2000 \mathrm{~ms}$; $\mathrm{TE}=29$ $\mathrm{ms}$; flip angle $=70^{\circ} ; \mathrm{FOV}=224 \mathrm{~mm}$; image matrix $=64 \times 64$; number of slices $=38$; voxel size $=3.5 \times 3.5 \times 3.5 \mathrm{~mm}$; total volumes 395 ).

\section{TMS sessions}

TMS sessions (conducted on a later date than the MRI scan) targeted the right hemisphere $\mathrm{S} 1$ on one day and the vertex on the other day, in an order counterbalanced across participants. The right hemisphere was selected on the basis of previous TMS studies investigating social modulation of touch (Bolognini et al., 2013). TMS sessions were separated by at least $24 \mathrm{~h}$ and were separated from any other TMS sessions in unrelated 


\begin{tabular}{|c|c|c|c|c|c|c|c|c|c|c|c|c|c|c|c|c|}
\hline Palm scan & $\begin{array}{l}B=\text { Brush } \\
R=\text { Rest }\end{array}$ & $\begin{array}{l}B \\
6 s\end{array}$ & $\begin{array}{c}\mathrm{R} \\
15 \mathrm{~s}\end{array}$ & $\begin{array}{l}B \\
6 \mathrm{~s}\end{array}$ & $\begin{array}{c}\mathrm{R} \\
15 \mathrm{~s}\end{array}$ & $\begin{array}{l}\mathrm{B} \\
6 \mathrm{~s}\end{array}$ & \begin{tabular}{c|c}
$\mathrm{R}$ & $\mathrm{B}$ \\
$15 \mathrm{~s}$ & $6 \mathrm{~s}$
\end{tabular} & $\begin{array}{c}\mathrm{R} \\
15 \mathrm{~s}\end{array}$ & \begin{tabular}{c|c}
$\mathrm{B}$ & $\mathrm{R}$ \\
$6 \mathrm{~s}$ & $15 \mathrm{~s}$
\end{tabular} & $\begin{array}{l}B \\
6 \mathrm{~s}\end{array}$ & $\begin{array}{c}\mathrm{R} \\
15 \mathrm{~s}\end{array}$ & \begin{tabular}{c|c}
$\mathrm{B}$ & $\mathrm{R}$ \\
$\mathbf{6 \mathrm { s }}$ & $15 \mathrm{~s}$
\end{tabular} & $\begin{array}{l}B \\
6 \mathrm{~s}\end{array}$ & $\begin{array}{c}\mathrm{R} \\
15 \mathrm{~s}\end{array}$ & $\begin{array}{c}\text { Rate } \\
\text { intensity } \\
8 \mathrm{~s} \\
\end{array}$ & \begin{tabular}{|c|} 
Rate \\
pleasantness \\
$8 \mathrm{~s}$ \\
\end{tabular} \\
\hline Fast brush & Rate & & Slor & $v$ bru & & & Rate & & Fast bru & & & Rate & & Slo & brush & Rate \\
\hline
\end{tabular}

\section{Back of hand scan}

\begin{tabular}{|l|l|l|l|l|l|l|l|}
\hline Slow brush & Rate & Slow brush & Rate & Fast brush & Rate & Fast brush \\
\hline
\end{tabular}

Figure 1. fMRI design. Brushing stimuli were delivered during two runs: one brushing the palm and one brushing the back of the hand. Each run contained 4 blocks: 2 fast brushing blocks $(30 \mathrm{~cm} / \mathrm{s})$ and 2 slow brushing blocks $(3 \mathrm{~cm} / \mathrm{s})$. Each block had $86 \mathrm{~s}$ periods of brushing with rest periods jittered around $15 \mathrm{~s}$. Each block was followed by a $16 \mathrm{~s}$ rating period: $8 \mathrm{~s}$ for rating intensity and $8 \mathrm{~s}$ for rating pleasantness. The order of the two runs was counterbalanced across subjects and the order of the four blocks was randomized within each run.

studies by at least 1 week. The vertex was selected as the control condition because TMS at this location produces sensation on the scalp, but should cause little to no brain activation due to the depth of the cortex beneath the scalp at this location. The vertex is frequently used as a control condition in rTMS studies and has generally been found to not alter somatosensory discriminative performance (Knecht et al., 2003; Duecker et al., 2013; Lockwood et al., 2013).

TMS was performed with a figure-eight coil (double $70 \mathrm{~mm}$ diameter) driven by a Super Rapid Transcranial Magnetic Stimulator (Magstim). The subject's resting motor threshold (RMT) was determined by the minimum intensity of pulses over the right motor cortex required to elicit visible thumb twitches in the subject's left hand on five of 10 trials using a standard localization procedure (Schutter and Van Honk, 2006). Then, $1 \mathrm{~Hz}$ rTMS was then administered at $110 \%$ RMT for 20 min over $\mathrm{S} 1$ or the vertex. The visual identification of RMT can lead to overestimation of RMT values compared with the common electromyography RMT procedure (Westin et al., 2014), so it is possible that rTMS was administered at closer to $120 \%$ RMT. Although suprathreshold stimulation can cause stronger distal activation (Bestmann et al., 2005), this level of intensity was chosen to be consistent with previous studies that have examined the role of S1 in social aspects of touch (Bolognini et al., 2011; Rossetti et al., 2012; Bolognini et al., 2013) in an attempt to obtain the best chance of finding effects of TMS on our measures of touch perception. The $S 1$ target and the motor target where RMT determination was initiated were derived from each subject's peak response to the brushing and motor fMRI tasks, respectively. $Z$-statistic maps of the brushing versus rest and movement versus rest contrasts, as well as each subject's structural MRI, were imported from FSL into Brainsight. The vertex target was placed manually above the interhemispheric fissure in the same coronal plane as the S1 target, falling approximately above the middle of the precentral gyrus (due to curvature of the central sulcus). The vertex is typically localized at the midline above the precentral gyrus (Okamoto et al., 2004), so we believe our neuro-navigated placement was consistent with typical manual localization of the vertex point. No subjects reported sensation or movement in their feet. The average MNI coordinate stimulated at the scalp was $(46,-28,72)$ for the $S 1$ condition and $(0,-22,92)$ for the vertex condition (Fig. 2$)$. The coil was aligned in the posterior-anterior direction at $0^{\circ}$ for the vertex condition and $\sim 45^{\circ}$ to the right of the midline for the $\mathrm{S} 1$ condition. The subject's structural MRI was coregistered to their head position, which was tracked in real time using a Brainsight TMS Navigation system (Rogue Research) that allowed us to navigate coil position relative to the target. During the 20 min of rTMS, the participant watched a time-lapse movie of landscapes with no audio. Participants wore earplugs during the rTMS stimulation and placed their left arm on the testing table to avoid additional somatosensory stimulation.

Participants completed two sensory tasks both before and after rTMS: a brushing task and a 2PD task. The order of these tasks was counterbalanced across subjects. These tasks were completed within $\sim 8 \mathrm{~min}$ of the termination of the rTMS to remain within conservative estimates of the

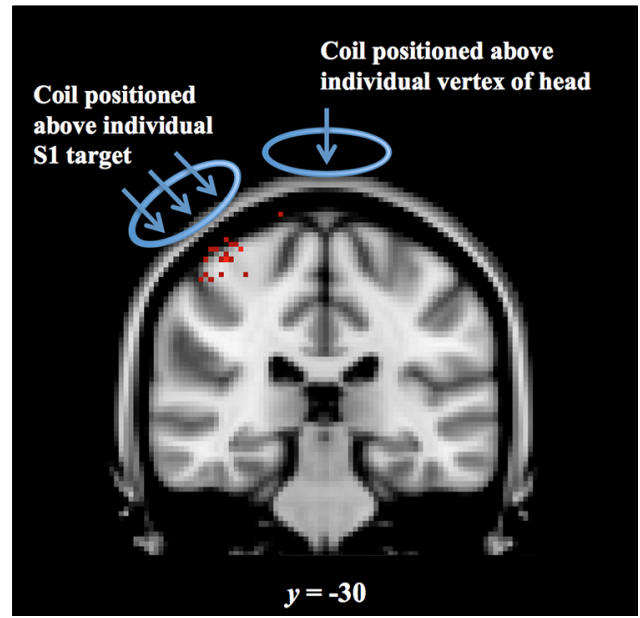

Figure 2. rTMS target placement. Each point represents an individual subject's right hemisphere primary somatosensory cortex $\mathrm{S} 1$ target (red) transformed into MNI space. The S1 target was individually selected based on the peak of the subject's $Z$-statistic map of brushing $>$ rest. The coil was aligned in the posterior-anterior direction at $\sim 45^{\circ}$ to the right of midline in the $S 1$ condition. In the vertex condition, the coil was placed directly above the interhemispheric fissure in the same coronal plane as individual subject's $\$ 1$ target. The coil was aligned in the posterior-anterior direction at $0^{\circ}$ to the midline. Each target is displayed at the section representing the group average $y$-coordinate (coronal) in MNI space.

duration of rTMS-induced cortical inhibition (Knecht et al., 2003). The brushing task was identical to the fMRI brushing task except that participants only experienced 1 trial $(6 \mathrm{~s})$ of each type of brushing and then immediately rated perceived intensity and pleasantness. The subject and the experimenter who conducted sensory testing were blinded to the TMS location during each session so that sensory testing could not be biased. The order of the four types of brushing was randomized. Fifteen of the 19 participants practiced the $2 \mathrm{PD}$ task once during the screening session.

In the 2PD task, participants were touched with one or two plastic tips on the thenar eminence of the palm of the left hand using an aesthesiometer (Lafayette Instrument). On each trial, subjects pressed a button on a response box to indicate whether they perceived one or two points. Two descending series of blocks were administered with tip separations of 10 , 8,6 , and $4 \mathrm{~mm}$ (unless the subject performed during their first session with $<75 \%$ accuracy at $10 \mathrm{~mm}$, in which case the distance was initially increased by $2 \mathrm{~mm}$, or at $>75 \%$ accuracy at $4 \mathrm{~mm}$, in which case testing continued to $2 \mathrm{~mm}$ ). Each block contained 5 trials of 2-point stimulation and 5 trials of 1-point stimulation. Four subjects at the beginning of the study received a slightly different set of distances spanning a similar range. For all subjects, all distances that were administered both before and after a given TMS session were analyzed so that all comparisons of 
2PD accuracy within a TMS session arise from identical within-session testing blocks.

Mood ratings were collected verbally at the beginning of each sensory testing block (good mood, bad mood, anxiety, and calmness scales anchored with $0=$ neutral and $10=$ extremely good/bad/calm/anxious).

\section{Data analysis}

fMRI analysis

Preprocessing. Data were preprocessed in FSL (Jenkinson et al., 2002; Smith et al., 2004; Woolrich et al., 2009; Jenkinson et al., 2012). Images were corrected for subject motion and aligned to the middle volume of each run (image registration: MCFLIRT; Jenkinson et al., 2002). Head motion did not exceed the acquired voxel size. Five-millimeter Gaussian smoothing was applied. The T1 brain volume was extracted from the skull using AFNI 3dSkullStrip and aligned to the mean functional EPI with Boundary-Based Registration.

Mass univariate general linear model analysis. For each subject, a voxelwise general linear model was conducted using FEAT (FMRI Expert Analysis Tool; part of FSL). Brushing, hand preparation/relaxation, and rating periods were modeled using a boxcar function convolved with the canonical hemodynamic response function. Twelve additional parameters of no interest were included to model rigid body translation and rotation during the alignment to standardized space (MNI $2 \mathrm{~mm}$ brain). BET (part of FSL) was used to mask activation outside the brain. A $100 \mathrm{~s}$ high-pass filter was applied.

Group-level analysis. A group analysis was performed to identify BOLD activity predicted by intensity and pleasantness ratings using FSL's mixed effects FLAME module (FMRIB's local analysis of mixed effects; Smith et al., 2004). Regressors for intensity and pleasantness ratings were included together in the analysis and contrasts were computed for intensity $>$ pleasantness and pleasantness $>$ intensity to identify brain areas with significant differences in intensity versus pleasantness representation, as well as for each parameter individually to identify correlations with either parameter in regions with significant differences. Images were thresholded at a $Z$-score of 3 and corrected for whole-brain multiple comparisons using Gaussian random field to select clusters significant at the $p<0.01$ level.

ROI analysis. A region of interest (ROI) was drawn by hand in FSL for $\mathrm{S} 1$ guided by the Harvard-Oxford cortical atlas and the group BOLD response to hand brushing. In addition, to verify our ROI findings in an independently defined ROI, a $5 \mathrm{~mm}$ spherical ROI was centered around the peak $\mathrm{S} 1$ voxel responding to left palm brushing described in McCabe et al. (2008). Mean COPE (contrast of parameter estimates) values were extracted from the ROIs for each subject for each brushing condition using Featquery (part of FSL). A general linear mixed-effects model was run in JMP version 11 (SAS Institute) with the following factors: brushing speed (fast or slow), brushing location (palm or back of hand), speed $\times$ location, pleasantness ratings, intensity ratings, and subjects as a random factor. Brushing order was also included as a first-order covariate of noninterest. The variance inflation factor in these analyses was 1.11 , indicating that results were not particularly influenced by multicollinearity.

\section{Analysis of sensory testing}

Before conducting analysis of the sensory testing, we checked for main effects of TMS session order (S1 or vertex in session 1) and task order (2PD or brushing administered first) on changes in 2PD accuracy and brushing ratings from before to after rTMS.

$2 P D$ accuracy. $2 \mathrm{PD}$ was scored for each distance as a percentage of correct trials out of the total number of trials. Because subjects were tested on different distances depending on their performance, distances were recoded into 4 levels (1-4) for each subject where $1=$ the lowest distance the subject was consistently tested on before and after both TMS sessions, 2 = the next lowest, and so on. Difference scores were calculated for each subject by subtracting 2PD accuracy before TMS from 2PD accuracy after TMS. A general linear mixed-effects model was run in JMP with the following factors: TMS session (S1 or vertex), distance level (1-4), distance $\times$ session, and subjects as a random factor. Post tests were conducted for each distance level (1-4) and corrected for multiple comparisons using a Bonferroni correction.

TMS brushing rating comparisons between TMS locations. Each analysis was conducted separately for intensity ratings and for pleasantness ratings. A paired $t$ test was conducted in JMP to test the effect of TMS session on average pre-post ratings. Differences in ratings at baseline and whether brushing speed affected ratings (brushing speed and subjects as a random factor) were also determined.

TMS brushing rating comparisons within each TMS location. For S1 and the vertex separately, one-sample $t$ tests were conducted to determine whether rating changes (before to after rTMS) differed significantly from zero for each brushing type separately and for the average of all brushing types. This analysis was conducted in the subset of subjects who exhibited reduced $2 \mathrm{PD}$ in the $\mathrm{S} 1$ condition to determine whether there were rating changes after S1 rTMS in those subjects assumed to have had successful reduced activation of $\mathrm{S} 1$.

Finally, to determine whether $2 \mathrm{PD}$ change was associated with rating changes, a general linear mixed-effects model was run in JMP for intensity and pleasantness separately with the following factors: TMS session ( $\mathrm{S} 1$ or vertex), $2 \mathrm{PD}$ change, TMS session $\times 2 \mathrm{PD}$ change, and subjects as a random effect (repeated measures). The effect of pleasantness ratings on intensity ratings was also tested in a linear mixed-effects model with pleasantness ratings and subjects as a random effect (repeated measures). This was tested for ratings collected before TMS, after TMS, and during fMRI. In addition, the interaction of TMS session and pre-post pleasantness ratings in predicting pre-post intensity ratings (with subjects as a random factor) were tested to determine whether TMS location caused any change in this relationship.

\section{Results}

\section{Brushing the hand activated somatosensory regions of the cortex}

All speeds and locations of brushing activated the somatosensory brain regions that we expected, including the primary and secondary somatosensory cortices, anterior and posterior insula, thalamus, and cerebellum. For the contrast of slow $>$ fast brushing on the back of the hand, significant clusters were found in the ACC (Fig. 3, Table 1); no significant clusters were found for the same contrast on the palm of the hand. Clusters were also found in the sensory and motor cortices for the back of the hand slow $>$ fast contrast, which could indicate slight differences in hand movement or tension during these brushing speeds.

\section{S1 activity correlates with intensity; ACC activity correlates with pleasantness}

fMRI brushing ratings are displayed in Figure 4. Ratings of intensity and pleasantness were inversely related within subjects $\left(F_{(1,205.8)}=44.0 ; p<0.0001\right)$, so both were included in each analysis. In the whole-brain analysis, several brain regions showed significantly greater representation of intensity than pleasantness and several areas showed greater representation of pleasantness than intensity (Table 2). We then looked at each predictor separately and found that, within subjects, intensity ratings but not pleasantness ratings correlated significantly with BOLD response in the right hemisphere (contralateral) S1, right insula, and bilateral S2 (statistical threshold $Z>3$; whole-brain cluster threshold $p<0.01$; Fig. 5, Table 3 ), all regions with significantly greater intensity representation than pleasantness representation (Table 2 ). In contrast, the only region that showed a significant positive correlation with pleasantness was a cluster with a peak in the pregenual ACC (pgACC) that extended into the dorsal ACC (Table 3); again, a region with significantly greater representation of pleasantness than intensity (Table 2). For both intensity and pleasantness ratings, the only regions showing significant negative correlations with BOLD response were in the 


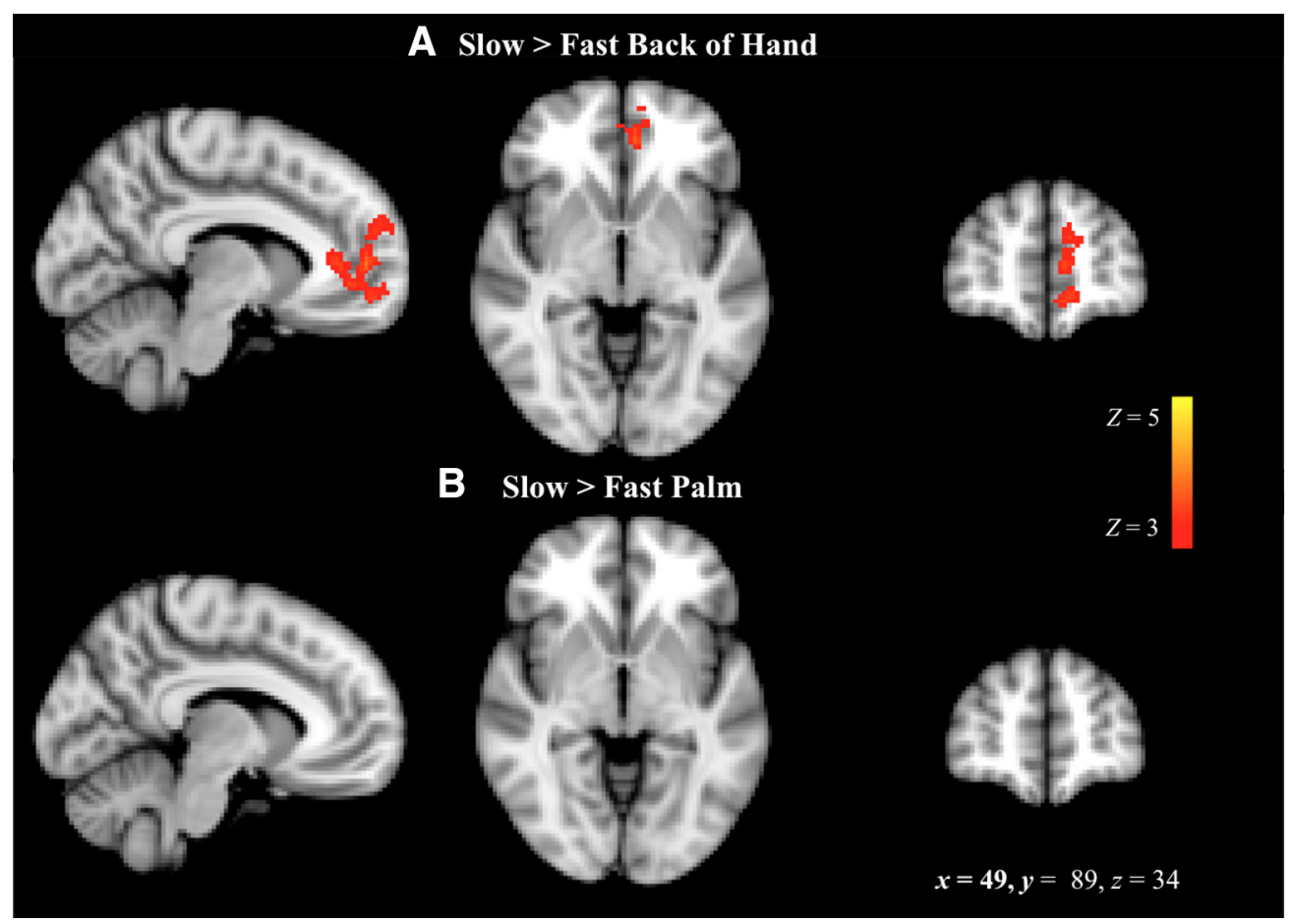

Figure 3. Slow $>$ fast brushing. The contrast of BOLD response to slow $>$ fast brushing was thresholded at $Z>3$ with whole-brain correction for multiple comparisons at the cluster level $(p<0.01) . A, 0 n$ the back of the hand, the left ACC, left motor cortex, and right somatosensory cortex had a greater response to slow than fast brushing. $B$, No regions showed a significantly greater response to slow than fast brushing on the palm. $x, y$, and $z$ are $\mathrm{MNI}$ coordinates corresponding to the left-right, anterior-posterior, and inferior-superior axes, respectively; $\mathrm{R}=\mathrm{L}$.

Table 1. Slow $>$ fast bushing on the back of the hand

\begin{tabular}{|c|c|c|c|c|c|}
\hline Slow $>$ fast back of hand & Hemisphere & Peak $x, y, z$ & Peak Z & No. of voxels & $p$-value \\
\hline Motor cortex & L & $-40,18,62$ & 3.82 & 465 & $p<0.00001$ \\
\hline Anterior cingulate cortex, medial prefrontal cortex, frontal pole & $\mathrm{L}$ & $-8,50,6$ & 3.92 & 390 & $p<0.00001$ \\
\hline Sensory cortex & $\mathrm{R}$ & $50,-4,40$ & 4.26 & 273 & $p=0.0002$ \\
\hline
\end{tabular}

Clusters are displayed above a statistical threshold of $Z>3$, whole-brain corrected for multiple comparisons $(p<0.01 ; n=26) . x, y$, and $z$ refer to MNI coordinates corresponding to the left-right, anterior-posterior, and inferior-superior axes, respectively.

inferior parietal and occipital lobes (Table 3). However, none of these regions showed significant differences between intensity and pleasantness (Table 2).

\section{ROI results confirm whole-brain results}

S1 BOLD response in our S1 ROI was significantly predicted by ratings of intensity $\left(F_{(1,172.5)}=13.44 ; p=0.0003\right)$ but not ratings of pleasantness $\left(F_{(1,191.2)}=0.50 ; p=0.48\right)$. Analysis of an independent hand S1 ROI (based on McCabe et al., 2008; see Materials and Methods) similarly found BOLD response significantly predicted by intensity $\left(F_{(1,173.6)}=4.34 ; p=0.039\right)$, but not pleasantness $\left(F_{(1,192)}=0.062 ; p=0.80\right)$.

\section{rTMS to $S 1$ alters $2 P D$}

There was a main effect of TMS location ( $\mathrm{S} 1$ vs vertex) on changes in 2PD accuracy $\left(F_{(1,121.3)}=6.09\right.$; two-tailed $p=0.015$, Cohen's $d=0.29)$, but no main effect of distance $\left(F_{(3,122.4)}=0.42 ; p=\right.$ $0.74)$. There was also a marginal interaction between TMS location and $2 \mathrm{PD}$ distance $\left(F_{(3,121.3)}=2.44\right.$; one-tailed $p=0.034$; Fig. 6). Post hoc tests showed that 2PD accuracy was significantly reduced more by S1 rTMS than by vertex rTMS at the smallest distance tested $\left(F_{(1,17)}=6.89\right.$, one-tailed $p=0.036$ after Bonferroni correction, Cohen's $d=1.00)$. At this smallest distance $2 \mathrm{PD}$ accuracy decreased $6.9 \%$ on average after S1 rTMS, but increased $1.1 \%$ on average after vertex rTMS. These results were not altered by excluding one subject who was an outlier on the 2PD task. There were no main effects of TMS session order or task order (2PD or brushing first) on changes in $2 \mathrm{PD}$ accuracy $\left(F_{(1,14.94)}=\right.$ $\left.0.37 ; p=0.51 ; F_{(1,14.85)}=0.45 ; p=0.55\right)$, so these covariates were not included in the analyses above.

\section{rTMS to $S 1$ alters ratings of brush intensity but}

\section{not pleasantness}

Brushing ratings between $r$ TMS locations

Ratings of brushing intensity and pleasantness did not differ between rTMS locations at baseline before receiving rTMS (intensity: $t_{(18)}=1.42, p=0.17$; pleasantness: $t_{(18)}=0.57, p=0.58$ ). For both TMS locations, participants provided higher intensity ratings for fast brushing (vertex $F_{(1,54)}=33.69, p=0.0002$; S1 $\left.F_{(1,54)}=39.86, p<0.0001\right)$ and higher pleasantness ratings for slow brushing (vertex $F_{(1,54)}=15.67, p=0.0002$; S1 $F_{(1,54)}=$ $28.36, p<0.0001$ ). There was no main effect of session (vertex or S1) on change in average brushing intensity $\left(t_{(18)}=0.40, p=\right.$ $0.70)$ or change in average pleasantness $\left(t_{(18)}=0.56, p=0.58\right)$. There were no main effects of TMS session order or task order on changes in ratings of brushing intensity $\left(F_{(1,16)}=0.11, p=0.92\right.$; $\left.F_{(1,16)}=1.64, p=0.22\right)$ or pleasantness $\left(F_{(1,16)}=0.07, p=0.79\right.$; $\left.F_{(1,16)}=1.22, p=0.29\right)$, so these covariates were not included in our analyses. 


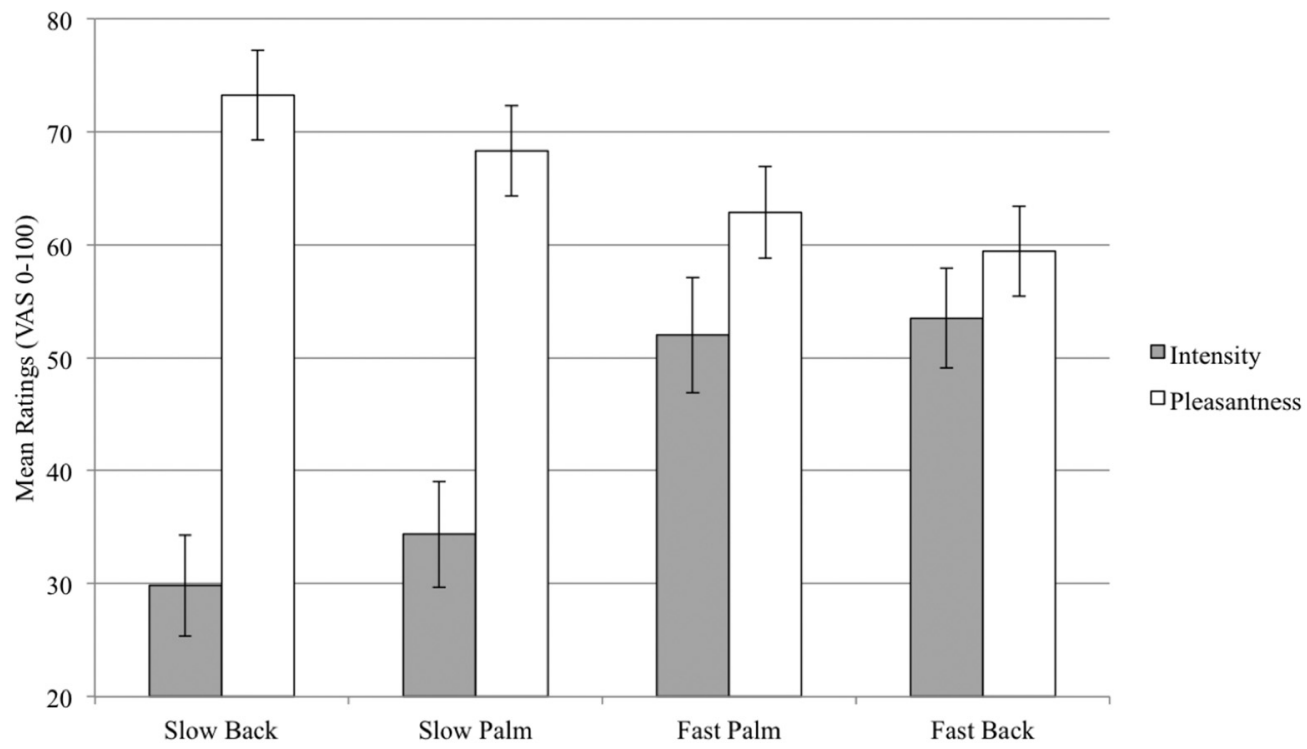

Figure 4. Brushing ratings. During the fMRI task, slow $(3 \mathrm{~cm} / \mathrm{s})$ and fast brushing $(30 \mathrm{~cm} / \mathrm{s})$ stimuli were delivered to the palm and back of the left hand. Each block of 8 stimuli was rated on a visual analog scale for intensity $(0=$ "no sensation"; $100=$ "the most intense sensation imaginable") and for pleasantness $(0=$ "the most unpleasant imaginable"; $100=$ "the most pleasant imaginable"). Error bars indicate \pm SEM.

Table 2. Whole-brain correlates of intensity versus pleasantness contrasts

\begin{tabular}{|c|c|c|c|c|c|}
\hline & Hemisphere & Peak $x, y, z$ & PeakZ & No. of voxels & $p$-value \\
\hline \multicolumn{6}{|l|}{ Intensity $>$ pleasantness } \\
\hline Primary somatosensory cortex & $\mathrm{R}$ & $28,-22,62$ & 5.78 & 1158 & $p<0.00001$ \\
\hline Secondary somatosensory cortex/posterior insula & $\mathrm{R}$ & $50,50,-24$ & 4.99 & 379 & $p<0.0001$ \\
\hline Secondary somatosensory cortex & L & $-62,-18,10$ & 4.69 & 360 & $p<0.0001$ \\
\hline \multicolumn{6}{|l|}{ Pleasantness $>$ intensity } \\
\hline Bilateral frontal cortex & L & $-10,38,0$ & 5.92 & 9347 & $p<0.00001$ \\
\hline White matter & L & $-36,-24,44$ & 4.41 & 594 & $p<0.00001$ \\
\hline Cerebellum & $\mathrm{R}$ & $20,-46,-36$ & 4.66 & 526 & $p<0.00001$ \\
\hline White matter & $\mathrm{L}$ & $-24,-30,-16$ & 4.50 & 363 & $p<0.0001$ \\
\hline Cerebellum & $\mathrm{L}$ & $-12,-46,-34$ & 4.59 & 272 & $p=0.0003$ \\
\hline Superior frontal gyrus & $\mathrm{L}$ & $-18,-6,70$ & 4.24 & 170 & $p=0.006$ \\
\hline
\end{tabular}

axes, respectively; $Z$ refers to the highest $Z$-score within a cluster. A positive Z-value indicates a positive correlation between the subject's ratings and the BOLD response.

Brushing ratings within each rTMS location

When we analyzed only subjects who showed decreased 2PD accuracy after S1 rTMS $(n=14)$, who were assumed to have S1 deactivation, there was a significant increase in average brushing intensity ratings after S1 rTMS $\left(t_{(13)}=3.38, p=0.005\right.$, Cohen's $d=0.93$ ) and in the slow palm brushing condition in particular $\left(t_{(13)}=3.5881\right.$, corrected $\left.p=0.01\right)$, but no changes after vertex rTMS $\left(t_{(13)}=0.35, p=0.73\right.$; Fig. $\left.7 A\right)$. In these subjects with decreased 2PD after S1 rTMS, there were no changes in ratings of brushing pleasantness for either rTMS location $\left(\mathrm{S} 1 t_{(13)}=0.83\right.$, $p=0.42$; vertex $\left.t_{(13)}=0.03, p=0.98\right)$. A smaller number of subjects $(n=8)$ decreased in 2PD in the vertex condition. These individuals did not show significant change in intensity perception in the vertex condition $\left(t_{(7)}=1.53, p=0.17\right)$ or $S 1$ condition $\left(t_{(7)}=0.25, p=0.81\right)$. For pleasantness ratings, we calculated that we had $80 \%$ power to observe an effect size of 6 points on the 100 point VAS scale, given a 2 -tailed $\alpha$ level of 0.05 and our observed SD of $\sim 10$ points. The actual observed mean difference was $\sim 1$ point on a 100 point rating scale, an effect size of 0.1 that would require a sample size of 620 subjects to observe significance. In contrast, we were able to detect the marginal change in intensity ratings of 4 points (among $2 \mathrm{PD}$ responders) on the same VAS scale, with similar SD in ratings to the pleasantness ratings.
As in the fMRI data, pleasantness and intensity ratings were correlated within-subjects both before TMS $\left(F_{(1,148.4)}=27.0, p<\right.$ $0.0001)$ and after TMS $\left(F_{(1,144.3)}=69.6, p<0.0001\right)$. This relationship was not affected by TMS $\left(F_{(1,147.3)}=0.88, p=0.35\right)$.

\section{Changes in 2PD correlated with changes in intensity ratings}

In the full study sample, changes in brushing intensity (from before to after rTMS) were significantly predicted by changes in 2PD accuracy $\left(F_{(1,31.06)}=9.94 ; p=0.004\right.$; Fig. $\left.7 B\right)$, but not by rTMS location $\left(F_{(1,18.1)}=0.00 ; p=0.96\right)$ or the interaction between changes in $2 \mathrm{PD}$ accuracy and rTMS location $\left(F_{(1,31.9)}=\right.$ $0.06 ; p=0.81)$. Average changes in pleasantness ratings were not predicted by $2 \mathrm{PD}$ accuracy change $\left(F_{(1,32.77)}=1.17, p=0.29\right)$, rTMS location $\left(F_{(1,17.48)}=0.10, p=0.75\right)$, or the interaction of these factors $\left(F_{(1,32.02)}=0.46, p=0.50\right)$.

\section{rTMS to $\mathrm{S} 1$ did not alter mood}

On average, the 19 subjects reported high levels of good mood $(7.06 \pm 1.85)$ and calm $(7.43 \pm 1.82)$ and low levels of bad mood $(0.75 \pm 0.95)$ and anxiety $(0.68 \pm 1.16)$ during the TMS sessions. Subjects were slightly more happy and calm after rTMS than before $\left(t_{(18)}=2.84, p=0.010 ; t_{(18)}=2.17, p=0.043\right)$ and this 


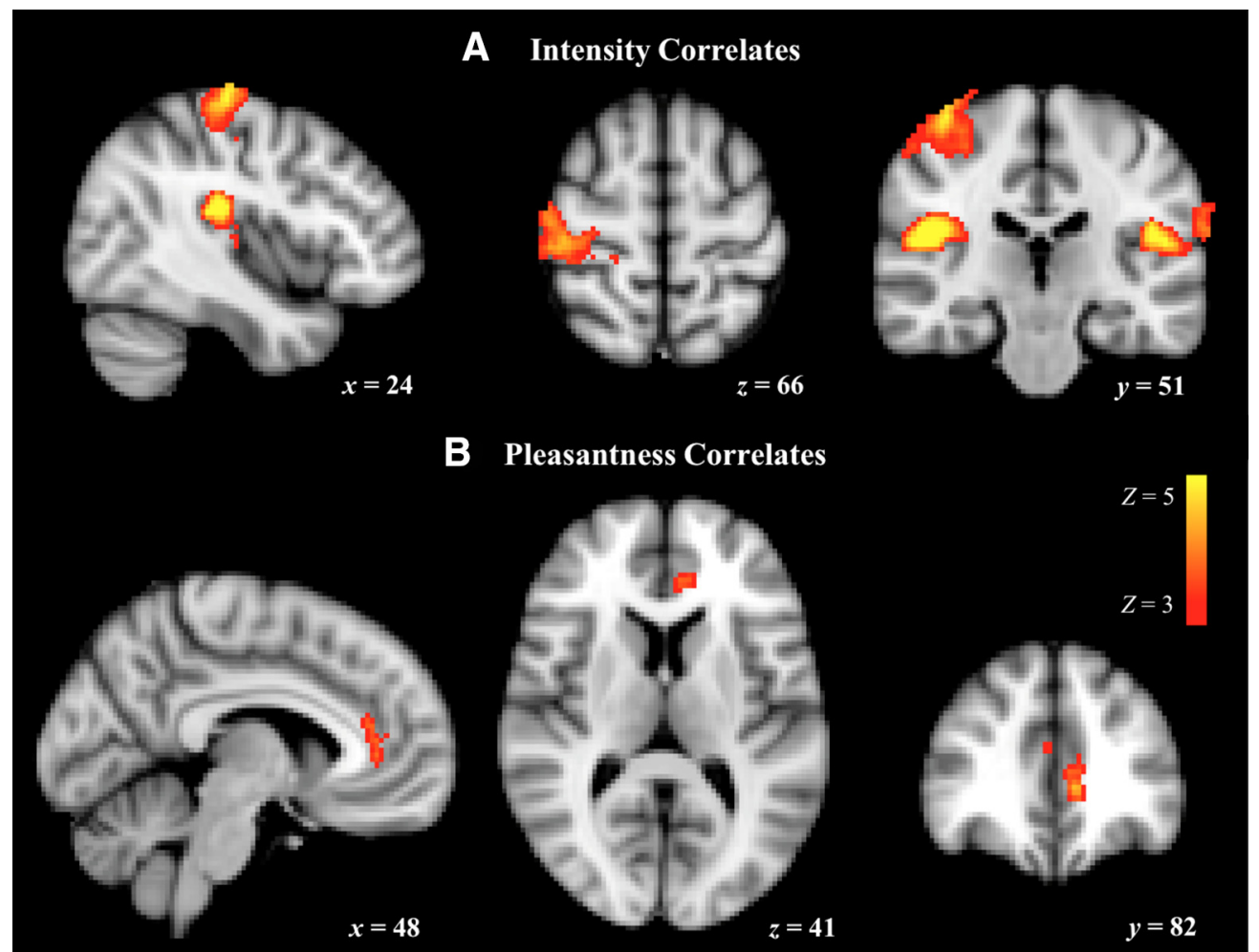

Figure 5. Whole-brain positive correlates of intensity and pleasantness. BOLD activation predicted by intensity and pleasantness ratings were thresholded at $Z>3$ with whole-brain correction for multiple comparisons at the cluster level $(p<0.01) . A$, Intensity ratings collected during the fMRI brushing task significantly predicted BOLD response in right $S 1$, right posterior insula, and bilateral S2. B, Pleasantness ratings significantly predicted BOLD response in the ACC. $x, y$, and $z$ refer to the MNI coordinates corresponding to the left-right, anterior-posterior, and inferiorsuperior axes, respectively; $R=L$.

\section{Table 3. Whole-brain correlates of intensity and pleasantness}

\begin{tabular}{|c|c|c|c|c|c|}
\hline & Hemisphere & Peak $x, y, z$ & Peak Z & Number of voxels & $p$-value \\
\hline \multicolumn{6}{|c|}{ Intensity: positive correlates (all regions significant in intensity > pleasantness; see Table 2) } \\
\hline Primary somatosensory cortex & $\mathrm{R}$ & $32,-32,72$ & 5.22 & 1062 & $p<0.00001$ \\
\hline \multirow[t]{2}{*}{ Secondary somatosensory cortex/posterior insula } & $\mathrm{R}$ & $46,-26,20$ & 6.52 & 745 & $p<0.00001$ \\
\hline & $\mathrm{L}$ & $-50,-22,16$ & 5.54 & 460 & $p<0.00001$ \\
\hline \multicolumn{6}{|l|}{ Intensity: negative correlates (not significant in contrast) } \\
\hline Angular gyrus & $\mathrm{R}$ & $26,-42,40$ & -5.57 & 2474 & $p<0.00001$ \\
\hline Supramarginal gyrus & L & $-22,-58,40$ & -4.44 & 277 & $p=0.0002$ \\
\hline \multirow[t]{3}{*}{ Occipital cortex } & L & $-24,-62,-6$ & -4.42 & 471 & $p<0.00001$ \\
\hline & $\mathrm{L}$ & $-22,-74,18$ & -4.25 & 212 & $p=0.002$ \\
\hline & $\mathrm{L}$ & $-48,-50,22$ & -3.77 & 184 & $p=0.004$ \\
\hline \multicolumn{6}{|c|}{ Pleasantness: positive correlates (all regions significant in pleasantness > intensity; see Table 2) } \\
\hline Anterior cingulate cortex & $\mathrm{L}$ & $-8,38,4$ & 4.46 & 196 & $p=0.003$ \\
\hline \multicolumn{6}{|c|}{ Pleasantness: negative correlates (not significant in contrast) } \\
\hline Occipital cortex & $\mathrm{R}$ & $28,-86,34$ & -5.09 & 300 & $p=0.0001$ \\
\hline
\end{tabular}

Clusters above a threshold of $Z>3$ are displayed with whole-brain correction for multiple comparisons $(p<0.01 ; n=26) . x, y$, and $z$ refer to the MNI coordinates corresponding to the left-right, anterior-posterior, and inferior-superior axes, respectively; $Z$ refers to the highest $Z$-score within a cluster. A positive Z-value indicates a positive correlation between the subject's ratings and the BOLD response.

did not differ by rTMS location $\left(F_{(1,16.8)}=0.24 ; p=0.63\right.$; $\left.F_{(1,18.1)}=0.93 ; p=0.35\right)$. There was not enough variability in mood ratings to use them as a covariate in our analyses.

\section{Discussion}

In the current study, we used fMRI and rTMS to examine the role of S1 in representations of touch intensity and pleasantness. Using fMRI during fast and slow brushing on the palm and back of the hand, we found that the perceived intensity of touch preferentially predicted activation of contralateral S1, posterior insula, and bilateral S2, whereas the perceived pleasantness of touch preferentially predicted activation only in the pgACC. Pleasantness ratings showed no correlation with S1 response in ROI analyses. Further, $1 \mathrm{~Hz}$ inhibitory rTMS over S1 significantly reduced tactile $2 \mathrm{PD}$, replicating Vidoni et al. (2010) and suggesting that we successfully reduced activation of $\mathrm{S} 1$, but this deactivation did not affect perception of touch pleasantness. Using decreased 2PD accuracy as an indicator of successful alteration of S1 activity, we observed increased ratings of brushing intensity after successful TMS to S1, although the effect was weak. In contrast, perceived touch pleasantness was unaffected by rTMS. Given the robust dissociation between the correlates of intensity and pleasantness ratings in our fMRI data and between ratings of fast and slow brushing, we believe that our scales were sensitive enough to meaningful 


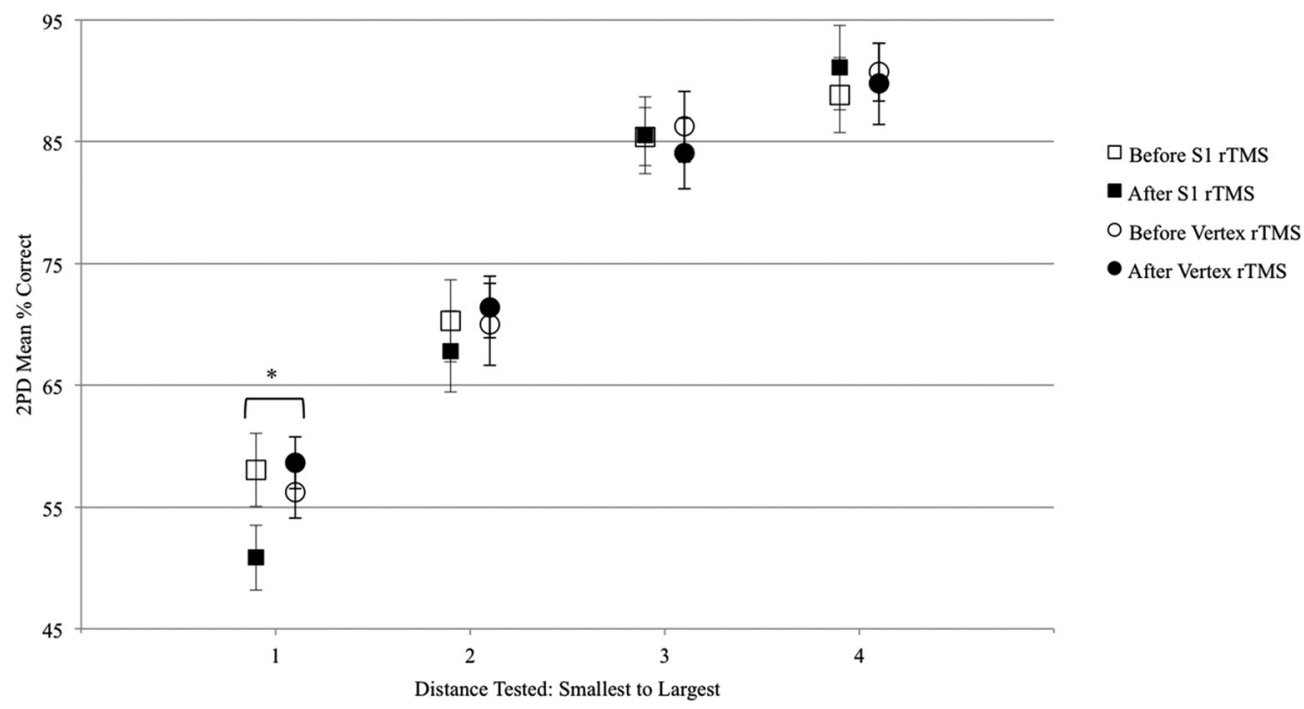

Figure 6. Effect of rTMS on 2PD accuracy. Participants were tested on 2PD before and after 20 min of inhibitory $1 \mathrm{~Hz}$ rTMS on 2 separate days. During the active session, rTMS was directed to S1 and, during the control session, rTMS was directed to the vertex. The 2PD task was administered as 2 descending series of blocks at tip distances of 2-10 mm (see Materials and Methods for details). Each block contained 5 trials of 2-point stimulation and 5 trials of 1-point stimulation. 2PD accuracy was reduced significantly more after rTMS to 51 than after rTMS to the vertex. In addition, there was a marginally significant interaction between rTMS session and distance. Post hoc tests showed that 2PD accuracy was significantly reduced after rTMS to $S 1$ at the smallest distance tested. $S 1$ before, $M=58.1, S D=11.1 ; S 1$ after, $M=50.8, S D=9.7$; vertex before, $M=56.3, S D=9.4 ;$ vertex after, $M=58.6, S D=9.2$. ${ }^{*}$ One-tailed $p<0.05$. Error bars indicate \pm SEM.

A

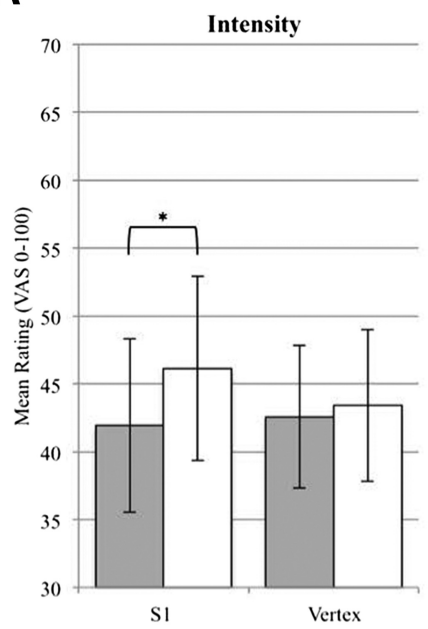

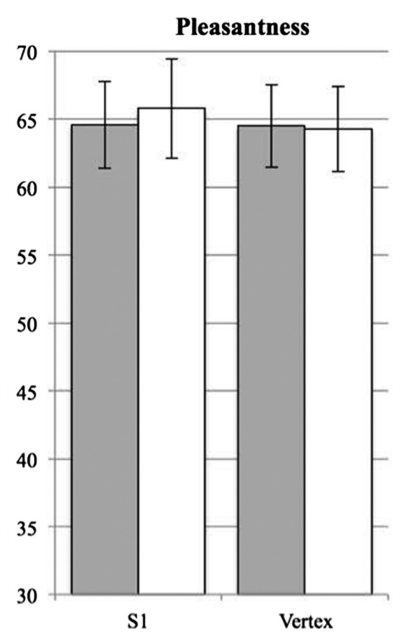

B

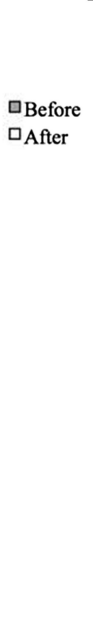

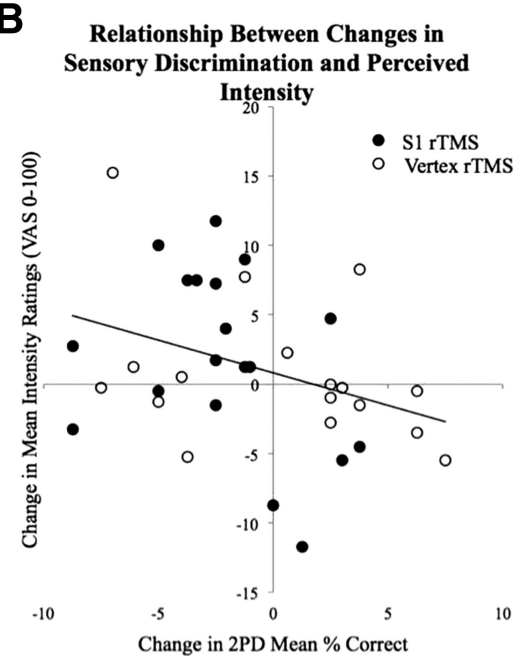

Figure 7. Perception of intensity and pleasantness after S1 rTMS. A, Subjects rated the intensity and pleasantness of fast and slow brushing on the palm and back of the hand before and after $20 \mathrm{~min}$ of $1 \mathrm{~Hz}$ rTMS. The subjects who showed a drop in 2PD performance after rTMS to S1 $(n=14)$ also showed an increase in intensity ratings but not in pleasantness ratings (averaged across brushing types) after rTMS to S1. Five subjects who did not show a drop in 2PD accuracy are not included in graph. ${ }^{*}$ Single-sample $t$ test, $p<0.05$. Error bars indicate \pm SEM. Intensity: $S 1$ before, $M=41.9, S D=26.0 ; S 1$ after, $M=46.1, S D=27.5$; vertex before, $M=45.6, S D=23.2 ;$ vertex after, $M=43.4, S D=24.7 ; p l e a s a n t n e s s: S 1$ before, $M=$ $64.6, S D=14.7 ; S 1$ after, $M=65.9, S D=15.9$; vertex before, $M=64.5, S D=15.2$; vertex after, $M=64.3, S D=15.3$. $B$, Changes in $2 P D$ accuracy from before to after rTMS significantly predicted changes in ratings of brushing intensity.

changes in CT stimulation. We also found an unexpected inverse relationship between changes in tactile discrimination accuracy and perceived touch intensity.

Together, these findings provide the most direct evidence to date that $S 1$ is involved preferentially in touch intensity and discrimination and does not play a strong role in perception of touch pleasantness.

Role of $\mathrm{S} 1$ cortex in discriminative but not affective touch Our data do not support the idea that $S 1$ cortex is critically involved in affective aspects of physical touch. In the fMRI portion of our study, BOLD response positively correlated with subjects' ratings of touch pleasantness only in the dorsal/pgACC; no correlation was found in S1.S1 response did correlate, however, with the perception of touch intensity. In the TMS portion of our study, subjects who showed reduced discriminative ability after $\mathrm{S} 1$ deactivation (but not those with reduced accuracy after vertex TMS) also had a significant alteration in intensity ratings, but no change in pleasantness ratings.

Nevertheless, some investigators have claimed that $\mathrm{S} 1$ may be important for affective aspects of touch. Gazzola et al. (2012) recently argued that $S 1$ activation may play a role in the affective significance of touch by showing that $\mathrm{S} 1$ response to sensual caress is modified by the perceived sex of the caresser. However, 
regions found in numerous other studies to be involved in affective touch, including insular and cingulate cortices, were not modulated in this paradigm. In addition, the study contained confounds related to attention and motivation that might account for the S1 modulation; subjects were instructed to be looking for a date. Finally, the visual and posterior parietal areas found in their connectivity analysis to modulate S1 are generally implicated in salience and cross-modal integration, not affect. McCabe et al. (2008) also reported a relationship between S1 activity and the perceived pleasantness of rubbing with a cream labeled as "rich moisturizing" versus "basic." However, this correlation was opposite that found by Gazzola et al. (2012).

Several other studies suggest the involvement of $S 1$ in affective touch, but contain confounds that complicate their interpretation. Studies that have used visual stimuli to modulate touch affect (Morrison et al., 2011; Bolognini et al., 2013) may have altered S1 activity through the visual component of observed touch, which has been shown to modulate S1 (Bolognini et al., 2011; Kuehn et al., 2013). Certain visual inputs may enhance sensorimotor-mirroring effects based on heightened attention or affective engagement in other brain regions (Bufalari and Ionta, 2013). Similarly, studies that have used physical stimuli to modulate touch pleasantness have failed to control for differences in texture, physical intensity, and perceived intensity of their stimuli (Francis et al., 1999; Rolls et al., 2003; Gordon et al., 2013), which strongly modulate S1 (Lin et al., 2003; Arthurs et al., 2004).

In sum, studies showing modulation of $S 1$ by pleasantness contain confounds that make it difficult to determine whether S1 was modulated by affect, attention, motivation, or sensorimotor mirroring. The current study overcomes the majority of these limitations by brushing with speeds that produce varied CT/A $\beta$ fiber stimulation and varied perceptual ratings of intensity and pleasantness without changing the texture or physical intensity of the touch stimulus itself. In addition, because fMRI can only demonstrate coactivation of S1 with pleasant touch, we conducted rTMS to test when S1 deactivation would affect touch pleasantness causally. Although manual administration adds some variability to the brushing, the experimenter brushing the subjects was blinded to TMS location, so TMS-induced changes in perception cannot be attributed to variability in the brushing stimulus. With both correlational and experimental evidence, we provide stronger evidence that $S 1$ is not causally involved in perception of touch pleasantness.

\section{Pleasantness representations only outside of S1}

The fMRI portion of our study found pleasantness correlations that also differed significantly from intensity correlations only in the pgACC. The ACC also responded more strongly to slow than fast brushing on the back of the hand but not the palm, consistent with the greater pleasantness of CT-optimal touch. The pgACC has been reported previously to represent the pleasantness or value of a stimulus (Grabenhorst and Rolls, 2011). Although the dorsal ACC has consistently been implicated in the appraisal of frightening and painful stimuli, the $\mathrm{MPFC} / \mathrm{OFC}$ and the ventral ACC, including the pgACC, have been consistently associated with positive emotion and regulation of negative emotion (Etkin et al., 2011; Grabenhorst and Rolls, 2011; Ellingsen et al., 2013). pgACC activity has been correlated with the pleasantness, but not intensity, of taste, smell, and temperature stimuli (de Araujo et al., 2005; Grabenhorst and Rolls, 2008; Grabenhorst et al., 2008) during both physical and cognitive manipulations of pleasantness. The ACC was also the sole region identified as responding to the pleasantness of touch massage by Lindgren et al. (2012), although this was a main effect of massage and not a correlational analysis. In addition, the unpleasantness of pain has been associated with activation in areas outside of S1, including the ACC (Rainville et al., 1997; Hofbauer et al., 2001; Rolls et al., 2003; Schreckenberger et al., 2005; Villemure and Bushnell, 2009; Lutz et al., 2013).

Several other brain areas showed greater association with pleasantness than with intensity, but these areas were not correlated with pleasantness alone. These areas included a large cluster in the frontal cortex including the ACC, in addition to clusters in the cerebellum and superior frontal gyrus. Representations of touch pleasantness have also been reported in the OFC (McCabe et al. (2008)) and insula (Kress et al., 2011), areas not found in the current study. Although there is evidence that CT input is processed in the insular cortex (Olausson et al., 2002) and the posterior insula often activates more strongly to CT targeted touch (Olausson et al., 2002; Björnsdotter et al., 2009; Kress et al., 2011; Gordon et al., 2013), only Kress et al. (2011) have reported a correlation between pleasantness ratings and insula response.

We also observed several brain areas that increased in activation with lower intensity or pleasantness ratings, but these areas did not show a significant difference between their representation of intensity and pleasantness. These regions may reflect default mode network engagement in the inferior parietal lobe (Buckner et al. (2008)), although the rest of the default mode network was not engaged. Occipital correlations might reflect wandering visual attention or greater attention to the visual brushing prompt on the screen when participants were less focused on the brushing sensation itself.

To demonstrate fully a double dissociation between representation of intensity in S1 and representation of pleasantness in the ACC, it would be ideal to attempt deactivation of the pgACC. However, selective stimulation of the pgACC is not yet possible. Our conclusions about pleasantness representation outside of S1 thus rest on correlational brain-imaging data and the lack of behavioral double dissociation remains a significant limitation of our study.

\section{How are sensory discrimination and intensity perception related?}

We found a significant correlation between TMS-induced changes in $2 \mathrm{PD}$ performance and intensity perception. Opposite to our original prediction, as discriminative ability decreased, perception of brushing intensity increased. Reducing activation of $S 1$ could induce compensatory activity in other brain areas that contribute to intensity perception (O'Shea et al., 2007), such as S2. S2 was strongly correlated with intensity ratings in our fMRI data and is causally implicated in judgments of pain intensity (Lockwood et al., 2013). In addition, TMS to S1 has been shown recently to cause changes in functional connectivity to a number of brain areas; theta-burst stimulation of S1 was found to alter functional connectivity with dorsal premotor cortex, cerebellum, basal ganglia, and anterior cingulate cortex (Valchev et al., 2015) and $1 \mathrm{~Hz}$ rTMS of left $\mathrm{S} 1$ was found to increase sensory response in right $\mathrm{S} 1$ (Meehan et al., 2011).

The inverse correlation between changes in 2PD accuracy and intensity ratings, however, occurred for both the S1 and vertex rTMS locations. Although no mean change was found in the vertex condition (and vertex stimulation generally produces null effects; Duecker et al., 2013), individual shifts in attention might shift the focus of sensory processing between sensory discrimination and intensity perception. Alterations in $2 \mathrm{PD}$ performance 
(strongly linked to S1) were correlated with changes in intensity perception, but not with changes in pleasantness perception, providing further evidence of a link between intensity perception and S1, but no link between pleasantness perception and S1.

\section{Summary and future directions}

In sum, our data support a causal role for right hemisphere $S 1$ in perception of touch discrimination, and likely also intensity, but not touch pleasantness. Our fMRI study found pleasantness representations in the ACC but not in S1. Subsequent (partial) deactivation of $\mathrm{S} 1$ decreased spatial discrimination and altered intensity but not pleasantness perception. Within-subject decreases in sensory discrimination were associated with increases in perceived tactile intensity, potentially related to changes in relative activation of S1 and other brain areas such as S2. Future studies might investigate more closely $\mathrm{S} 2$ and its coding of intensity when S1 activity is diminished. In addition, more work is needed to clarify how S1 may be modulated indirectly by affect through changes in attention, expectation, motivation, or visual input and whether our finding generalizes to left hemisphere S1. rTMS might also be applied to investigate the causal role of other brain areas in the perception of touch pleasantness and affect more generally, although TMS is currently unable to target deeper cortical areas such as the pgACC selectively.

\section{References}

Arthurs OJ, Johansen-Berg H, Matthews PM, Boniface SJ (2004) Attention differentially modulates the coupling of $\mathrm{AMRI}$ BOLD and evoked potential signal amplitudes in the human somatosensory cortex. Exp Brain Res 157:269-274. Medline

Bestmann S, Baudewig J, Siebner HR, Rothwell JC, Frahm J (2005) BOLD MRI responses to repetitive TMS over human dorsal premotor cortex. Neuroimage 28:22-29. CrossRef Medline

Björnsdotter M, Löken L, Olausson H, Vallbo A, Wessberg J (2009) Somatotopic organization of gentle touch processing in the posterior insular cortex. J Neurosci 29:9314-9320. CrossRef Medline

Bolognini N, Rossetti A, Maravita A, Miniussi C (2011) Seeing touch in the somatosensory cortex: a TMS study of the visual perception of touch. Hum Brain Mapp 32:2104-2114. CrossRef Medline

Bolognini N, Rossetti A, Convento S, Vallar G (2013) Understanding others' feelings: the role of the right primary somatosensory cortex in encoding the affective valence of others' touch. J Neurosci 33:4201-4205. CrossRef Medline

Buckner RL, Andrews-Hanna JR, Schacter DL (2008) The brain's default network. Ann N Y Acad Sci 1124:1-38. CrossRef Medline

Bufalari I, Ionta S (2013) The social and personality neuroscience of empathy for pain and touch. Front Hum Neurosci 7:393. CrossRef Medline

Chen R, Classen J, Gerloff C, Celnik P, Wassermann EM, Hallett M, Cohen LG (1997) Depression of motor cortex excitability by low-frequency transcranial magnetic stimulation. Neurology 48:1398-1403. CrossRef Medline

Cohen LG, Bandinelli S, Sato S, Kufta C, Hallett M (1991) Attenuation in detection of somatosensory stimuli by transcranial magnetic stimulation. Electroencephalogr Clin Neurophysiol 81:366-376. CrossRef Medline

Craig A (2013) An interoceptive neuroanatomical perspective on feelings, energy, and effort. Behav Brain Sci 36:685-686. CrossRef Medline

de Araujo IE, Rolls ET, Velazco MI, Margot C, Cayeux I (2005) Cognitive modulation of olfactory processing. Neuron 46:671-679. CrossRef Medline

Duecker F, de Graaf TA, Jacobs C, Sack AT (2013) Time-and taskdependent non-neural effects of real and sham TMS. PLoS One 8:e73813. CrossRef Medline

Ellingsen DM, Wessberg J, Eikemo M, Liljencrantz J, Endestad T, Olausson H, Leknes S (2013) Placebo improves pleasure and pain through opposite modulation of sensory processing. Proc Natl Acad Sci U S A 110:1799317998. CrossRef Medline

Etkin A, Egner T, Kalisch R (2011) Emotional processing in anterior cingulate and medial prefrontal cortex. Trends Cogn Sci 15:85-93. CrossRef Medline
Francis S, Rolls ET, Bowtell R, McGlone F, O’Doherty J, Browning A, Clare S, Smith E (1999) The representation of pleasant touch in the brain and its relationship with taste and olfactory areas. Neuroreport 10:453-459. CrossRef Medline

Gazzola V, Spezio ML, Etzel JA, Castelli F, Adolphs R, Keysers C (2012) Primary somatosensory cortex discriminates affective significance in social touch. Proc Natl Acad Sci U S A 109:E1657-E1666. CrossRef Medline

Gordon I, Voos AC, Bennett RH, Bolling DZ, Pelphrey KA, Kaiser MD (2013) Brain mechanisms for processing affective touch. Hum Brain Mapp 34:914-922. CrossRef Medline

Grabenhorst F, Rolls ET (2008) Selective attention to affective value alters how the brain processes taste stimuli. Eur J Neurosci 27:723-729. CrossRef Medline

Grabenhorst F, Rolls ET (2011) Value, pleasure and choice in the ventral prefrontal cortex. Trends Cogn Sci 15:56-67. CrossRef Medline

Grabenhorst F, Rolls ET, Bilderbeck A (2008) How cognition modulates affective responses to taste and flavor: top-down influences on the orbitofrontal and pregenual cingulate cortices. Cereb Cortex 18:1549-1559. CrossRef Medline

Hallett M (2007) Transcranial magnetic stimulation: a primer. Neuron 55: 187-199. CrossRef Medline

Hofbauer RK, Rainville P, Duncan GH, Bushnell MC (2001) Cortical representation of the sensory dimension of pain. J Neurophysiol 86:402-411. Medline

Jenkinson M, Bannister P, Brady M, Smith S (2002) Improved optimization for the robust and accurate linear registration and motion correction of brain images. Neuroimage 17:825-841. CrossRef Medline

Jenkinson M, Beckmann CF, Behrens TE, Woolrich MW, Smith SM (2012) FSL. Neuroimage 62:782-790. CrossRef Medline

Knecht S, Ellger T, Breitenstein C, Bernd Ringelstein E, Henningsen $\mathrm{H}$ (2003) Changing cortical excitability with low-frequency transcranial magnetic stimulation can induce sustained disruption of tactile perception. Biol Psychiatry 53:175-179. CrossRef Medline

Kress IU, Minati L, Ferraro S, Critchley HD (2011) Direct skin-to-skin vs indirect touch modulates neural responses to stroking vs tapping. Neuroreport 22:646-651. CrossRef Medline

Kuehn E, Trampel R, Mueller K, Turner R, Schütz-Bosbach S (2013) Judging roughness by sight: a 7-tesla fMRI study on responsivity of the primary somatosensory cortex during observed touch of self and others. Hum Brain Mapp 34:1882-1895. CrossRef Medline

Lin YY, Shih YH, Chen JT, Hsieh JC, Yeh TC, Liao KK, Kao CD, Lin KP, Wu ZA, Ho LT (2003) Differential effects of stimulus intensity on peripheral and neuromagnetic cortical responses to median nerve stimulation. Neuroimage 20:909-917. CrossRef Medline

Lindgren L, Westling G, Brulin C, Lehtipalo S, Andersson M, Nyberg L (2012) Pleasant human touch is represented in pregenual anterior cingulate cortex. Neuroimage 59:3427-3432. CrossRef Medline

Lockwood PL, Iannetti GD, Haggard P (2013) Transcranial magnetic stimulation over human secondary somatosensory cortex disrupts perception of pain intensity. Cortex 49:2201-2209. CrossRef Medline

Loggia ML, Mogil JS, Bushnell MC (2008) Experimentally induced mood changes preferentially affect pain unpleasantness. J Pain 9:784-791. CrossRef Medline

Löken LS, Wessberg J, Morrison I, McGlone F, Olausson H (2009) Coding of pleasant touch by unmyelinated afferents in humans. Nat Neurosci 12:547-548. CrossRef Medline

Lundblad LC, Olausson HW, Hermansson AK, Wasling HB (2011) Cortical processing of tactile direction discrimination based on spatiotemporal cues in man. Neurosci Lett 501:45-49. CrossRef Medline

Lutz A, McFarlin DR, Perlman DM, Salomons TV, Davidson RJ (2013) Altered anterior insula activation during anticipation and experience of painful stimuli in expert meditators. Neuroimage 64:538-546. CrossRef Medline

Maeda F, Keenan JP, Tormos JM, Topka H, Pascual-Leone A (2000) Modulation of corticospinal excitability by repetitive transcranial magnetic stimulation. Clin Neurophysiol 111:800-805. CrossRef Medline

McCabe C, Rolls ET, Bilderbeck A, McGlone F (2008) Cognitive influences on the affective representation of touch and the sight of touch in the human brain. Soc Cogn Affect Neurosci 3:97-108. CrossRef Medline

Meehan SK, Linsdell MA, Handy TC, Boyd LA (2011) Interhemispheric enhancement of somatosensory cortical excitability through contralateral 
repetitive transcranial magnetic stimulation. Clin Neurophysiol 122: 1637-1644. CrossRef Medline

Morrison I, Björnsdotter M, Olausson H (2011) Vicarious responses to social touch in posterior insular cortex are tuned to pleasant caressing speeds. J Neurosci 31:9554-9562. CrossRef Medline

Okamoto M, Dan H, Sakamoto K, Takeo K, Shimizu K, Kohno S, Oda I, Isobe S, Suzuki T, Kohyama K, Dan I (2004) Three-dimensional probabilistic anatomical cranio-cerebral correlation via the international 10-20 system oriented for transcranial functional brain mapping. Neuroimage 21: 99-111. CrossRef Medline

Olausson H, Lamarre Y, Backlund H, Morin C, Wallin BG, Starck G, Ekholm S, Strigo I, Worsley K, Vallbo AB, Bushnell MC (2002) Unmyelinated tactile afferents signal touch and project to insular cortex. Nat Neurosci 5:900-904. CrossRef Medline

Olausson H, Cole J, Rylander K, McGlone F, Lamarre Y, Wallin BG, Krämer H, Wessberg J, Elam M, Bushnell MC, Vallbo A (2008) Functional role of unmyelinated tactile afferents in human hairy skin: sympathetic response and perceptual localization. Exp Brain Res 184:135-140. Medline

O'Shea J, Johansen-Berg H, Trief D, Göbel S, Rushworth MF (2007) Functionally specific reorganization in human premotor cortex. Neuron 54: 479-490. CrossRef Medline

Rainville P, Feine JS, Bushnell MC, Duncan GH (1992) A psychophysical comparison of sensory and affective responses to four modalities of experimental pain. Somatosens Mot Res 9:265-277. CrossRef Medline

Rainville P, Duncan GH, Price DD, Carrier B, Bushnell MC (1997) Pain affect encoded in human anterior cingulate but not somatosensory cortex. Science 277:968-971. CrossRef Medline

Rolls ET, O'Doherty J, Kringelbach ML, Francis S, Bowtell R, McGlone F (2003) Representations of pleasant and painful touch in the human orbitofrontal and cingulate cortices. Cereb Cortex 13:308-317. CrossRef Medline

Rossetti A, Miniussi C, Maravita A, Bolognini N (2012) Visual perception of bodily interactions in the primary somatosensory cortex. Eur J Neurosci 36:2317-2323. CrossRef Medline

Rossi S, Hallett M, Rossini PM, Pascual-Leone A; Safety of TMS Consensus Group (2009) Safety, ethical considerations, and application guidelines for the use of transcranial magnetic stimulation in clinical practice and research. Clin Neurophysiol 120:2008-2039. CrossRef Medline

Schneider SA, Pleger B, Draganski B, Cordivari C, Rothwell JC, Bhatia KP, Dolan RJ (2010) Modulatory effects of 5Hz rTMS over the primary somatosensory cortex in focal dystonia: an fMRI-TMS study. Mov Disord 25:76-83. CrossRef Medline

Schreckenberger M, Siessmeier T, Viertmann A, Landvogt C, Buchholz HG, Rolke R, Treede RD, Bartenstein P, Birklein F (2005) The unpleasantness of tonic pain is encoded by the insular cortex. Neurology 64: 1175-1183. CrossRef Medline

Schutter DJ, van Honk J (2006) A standardized motor threshold estimation procedure for transcranial magnetic stimulation research. J ECT 22: 176-178. CrossRef Medline

Sheehan DV, Janavs J, Baker R, Harnett-Sheehan K, Knapp E, Sheehan M, Lecrubier Y, Weiller E, Hergueta T, Amorim P, Bonora LI, Lepine JP (1998) MINI-Mini International Neuropsychiatric Interview-English Version 5.0.0-DSM-IV. J Clin Psychiatry 59:34-57.

Smith SM, Jenkinson M, Woolrich MW, Beckmann CF, Behrens TE, Johansen-Berg H, Bannister PR, De Luca M, Drobnjak I, Flitney DE, Niazy RK, Saunders J, Vickers J, Zhang Y, De Stefano N, Brady JM, Matthews PM (2004) Advances in functional and structural MR image analysis and implementation as FSL. Neuroimage 23:S208-S219. CrossRef Medline

Sterman AB, Schaumburg HH, Asbury AK (1980) The acute sensory neuronopathy syndrome: a distinct clinical entity. Ann Neurol 7:354-358. CrossRef Medline

Tegenthoff M, Ragert P, Pleger B, Schwenkreis P, Förster AF, Nicolas V, Dinse HR (2005) Improvement of tactile discrimination performance and enlargement of cortical somatosensory maps after $5 \mathrm{~Hz}$ rTMS. PLoS Biol 3:e362. CrossRef Medline

Triscoli C, Olausson H, Sailer U, Ignell H, Croy I (2013) CT-optimized skin stroking delivered by hand or robot is comparable. Front Behav Neurosci 7:208. CrossRef Medline

Valchev N, Ćurčić-Blake B, Renken RJ, Avenanti A, Keysers C, Gazzola V, Maurits NM (2015) cTBS delivered to the left somatosensory cortex changes its functional connectivity during rest. Neuroimage 114: 386-397. CrossRef Medline

Vallbo AB, Olausson H, Wessberg J (1999) Unmyelinated afferents constitute a second system coding tactile stimuli of the human hairy skin. J Neurophysiol 81:2753-2763. Medline

Vidoni ED, Acerra NE, Dao E, Meehan SK, Boyd LA (2010) Role of the primary somatosensory cortex in motor learning: an rTMS study. Neurobiol Learn Mem 93:532-539. CrossRef Medline

Villemure C, Bushnell MC (2009) Mood influences supraspinal pain processing separately from attention. J Neurosci 29:705-715. CrossRef Medline

Villemure C, Slotnick BM, Bushnell MC (2003) Effects of odors on pain perception: deciphering the roles of emotion and attention. Pain 106: 101-108. CrossRef Medline

Wassermann EM, Zimmermann T (2012) Transcranial magnetic brain stimulation: therapeutic promises and scientific gaps. Pharmacol Ther 133:98-107. CrossRef Medline

Westin GG, Bassi BD, Lisanby SH, Luber B; New York State Psychiatric Institute, NY, USA (2014) Determination of motor threshold using visual observation overestimates transcranial magnetic stimulation dosage: Safety implications. Clin Neurophysiol 125:142-147. CrossRef Medline

Woolrich MW, Jbabdi S, Patenaude B, Chappell M, Makni S, Behrens T, Beckmann C, Jenkinson M, Smith SM (2009) Bayesian analysis of neuroimaging data in FSL. Neuroimage 45:S173-S186. CrossRef Medline 